\title{
A TARDE DE UM POETA DORMINDO OU CONSIDERAÇÕES SOBRE O FAUNO
}

\author{
Tiago Hermano Breunig \\ Doutorando em Teoria Literária PPGL/UFSC/CNPq \\ Nada é mais seu do que seus sonhos! Nada é mais sua obra! \\ Conteúdo, forma, duração, ator, espectador - nessas comédias vocês próprios são \\ tudo! \\ Nietzsche $^{1}$
}

I.

Em "Considerações sobre o poeta dormindo", em que reivindica a "sombra" do sonho que alega esquecida pelos estudos da psicologia que se ocupa com o sonho, o poeta João Cabral de Melo Neto aborda as relações entre a poesia e o poeta e o sono. João Cabral concebe o "sono como fonte de poema", o qual se manifesta para o poeta como um estado ausente, emudecido e impotente, o que se antecipa na inscrição dos versos de Willy Lewin que introduzem a tese apresentada ao Congresso de Poesia do Recife em 1941 (Lewin apud Melo Neto, 1994, p.685): ${ }^{2}$

\footnotetext{
O sono, um mar de onde nasce

Um mundo informe e absurdo,

Vem molhar a minha face:

Caio num ponto morto e surdo.
}

Embora postule uma relação de causa e efeito entre o sono e o sonho, João Cabral reitera que o sono difere do sonho, de modo que o sonho, caracterizado por uma finitude, pode ser transmitido, configurando como que uma obra. Para tanto, e na medida em que pode ser evocado e explorado por meio da recordação, o sonho requer um "esforço de reconstituição":

O sonho é uma coisa que pode ser evocada, que se evoca. Cuja exploração fazemos através da memória. Um poema que nos comoverá todas as vezes que sobre nós mesmos exercermos um esforço de reconstituição. Porque é preciso lembrar que o sonho é uma obra cumprida, uma obra em si. Que se assiste. Esta fabulosa experiência pode ser evocada, narrada. Como a poesia, ou por outra, em virtude da poesia que ela traz consigo, apenas pode ser transmitida (p. 686).

1 NIETZSCHE, F. W. Aurora: reflexões sobre os preconceitos morais. São Paulo: Companhia das Letras, 2004.

2 Todas as citações da obra de João Cabral de Melo Neto foram tomadas de Obra completa. Rio de Janeiro: Nova Aguilar, 1994. Todas as referências entre parêntesis correspondem a esta edição. 
O sono, por outro lado, impossibilita a "percepção" e se configura, assim, como um estado "em que estamos ausentes" e, portanto, emudecidos. Se, entretanto, estamos emudecidos no estado de sono, o sonho, justamente por sua possibilidade de transmissibilidade por meio de um processo de reconstituição compreendido sob o signo da poesia, emerge prontamente como a "linguagem natural" do sono. No entanto, o sono, na medida em que provoca o adormecimento, confere ao sonho uma impossibilidade de ação, o que implica em uma atitude ativa e ao mesmo tempo passiva diante do sonho. E a "atitude do homem", como descreve o poeta, "diante do sonho", a qual se caracteriza pela atividade e passividade, fundamenta a figura do "homem adormecido" evocada pelo poeta:

Ambos: os acontecimentos do sonho e o homem adormecido, profundamente marcados pela presença mesma do sono, essa presença que não é de nenhum modo, apenas a ausência de nossas vinte e quatro horas, mas a visão de um território que não sabemos, do qual voltamos pesados, marcados por essa nostalgia de mar alto (p. 687).

A despeito da poeticidade do sono em si e da palavra mesmo que, segundo o poeta, parece se prolongar no escuro, o sono se oferece como apronto para o poeta, em detrimento de material ou objeto para o poema, exercendo sobre o poeta uma "vocação para o sobrenatural". Nesse sentido, o sono influencia a poesia de dois modos, a saber, por uma "predisposição" do sono para a poesia que se realiza, segundo a tese cabralina, por um lado, pela abstração do tempo e, por outro, pela ideia de morte, correlacionada com a abstração do tempo na medida em que, "sendo como que um movimento para o eterno", o sono impulsiona o poeta “contra o mundo, contra o tempo.” E, outro modo pelo qual o sono influencia a poesia, por uma promoção pelo sono de uma fusão de sentimentos e recordações, por meio da qual "o sono favorece a formação de uma zona obscura (um tempo obscuro)", caracterizada pelo adormecimento dos sentidos sensoriais, promovendo os elementos do poema que o poeta, "andando a longas pernadas dentro de sua noite", surpreende inconscientemente sobre o papel (p. 688).

Ora, assim que os modos pelos quais o sono influencia a poesia se condensam nos versos de Willy Lewin que introduzem a tese cabralina antecipando o tema do sono como fonte de poema, manifesto como um estado ausente, emudecido e impotente. Nesse sentido, o que emerge do mar e que equivale ao sono, nos referidos versos, condiz com o poema, e o ponto morto e surdo, com o estado do poeta surpreendido pelo poema. Afinal, ao poeta falta a percepção objetiva do que acontece durante o sono que, assim, em detrimento de inspirar, conclui João Cabral, fecunda a poesia "com seu sopro 
noturno", que move intemporalmente a poesia pelo mar alto evocado pelo poeta (p. 688).

Ao lado da falta de percepção objetiva do sono, o aspecto vago e misterioso que o caracteriza reporta o autor a uma impossibilidade de comunicação a seu respeito, uma vez que a linguagem parece insuficiente diante do sono. Com isso, o poeta postula uma recusa da objetividade, que concerne ao que, na qualidade de objeto, pode ser percebido pelos sentidos ou pelo intelecto, o que, por conseguinte, evoca a relação entre sujeito e objeto. O sonho, obra e linguagem natural do sono, aparece, por sua vez, como algo sobre o qual se pode refletir criticamente, por meio da atitude simultaneamente ativa e passiva provocada pelo sonho, remetendo a uma relação intimamente correlacionada inclusive com a referida atitude, ou seja, a oposição entre sujeito e objeto, conservada invariavelmente nas concepções de representação e de razão.

Aqui a poesia converge com a filosofia, contrariando o "antigo diferendo entre a filosofia e a poesia" (Platão, 1996, p. 475) evocado por Platão ao proscrever a poesia. Platão recusa a poesia na medida em que a julga incapaz de deter a verdade, considerando que a filosofia, a verdadeira filosofia, comparece, por sua vez, como a ascenção para a verdade e a realidade, cuja analogia consiste na contemplação do Sol, correlato da Ideia (Platão, 1996, p. 319). Por outro lado, Platão remete a contemplação mediante os sentidos e, por conseguinte, as imagens, justamente a um sonho:

\footnotetext{
Quem não for capaz de definir com palavras a ideia do bem, separando-a de todas as outras, e, como se estivesse numa batalha, exaurindo todas as refutações, esforçando-se por dar provas, não através do que parece, mas do que é, avançar através de todas estas objeções com um raciocínio infalível - não dirás que uma pessoa nestas condições não conhece o bem em si, nem qualquer outro bem, mas, se acaso toma contato com alguma imagem, é pela opinião, e não pela ciência que agarra nela, e que a sua vida atual a passa a sonhar e a dormir, pois, antes de despertar dela aqui, primeiro descerá ao Hades para lá cair num sono completo? (Platão, 1996, p. 351).
}

A partir de uma contemplação que se insinua, contrariamente ao modelo proposto por Platão, na figura do "homem adormecido", indiferente ao Sol que ilumina a tarde e no qual, afinal, o sono se manifesta nos "sinais de uma contemplação" que indica "um sinal de vida" (p. 687), a poesia ou o sonho - motivo constitutivo de um antigo problema em que comparece como oposto da realidade, para a qual a filosofia se oferece como a promessa do despertar, e em que, entretanto, a realidade se esvai em recusa da vida aparece finalmente como forma de conhecimento de uma verdade, produzida, no entanto, apenas pela arte, conforme a relação da filosofia com a arte como concebe Alain Badiou.

II. 
Nos mesmos anos em que discorre sobre suas considerações sobre o poeta dormindo, João Cabral escreve o livro de poemas "Pedra do sono" que, dedicado a Willy Lewin, brinda o leitor com o consagrado verso mallarmeano "Solitude, récif, étoile...". O sentido profundo da inscrição do verso do autor de "Salut" se revela na medida em que se compreende o papel fundamental que o sono assume em sua obra, sobretudo em "L'Après-midi d'un faune", em que o poeta retrata um fauno - cuja flauta, segundo a mitologia, induz ao sono - a recordar um acontecimento. Com efeito, o "esforço de reconstituição" que, na tese cabralina, permite, por meio da recordação, reconstituir um sonho ou um poema, parece ocupar o fauno, cuja reconstituição de um acontecimento que pode ter sido apenas um sonho (Mallarmé, 1984, p.50):

Ces nymphes, je les veux perpétuer.

$$
\text { Si clair, }
$$

Leur incarnat léger, qu'il voltige dans l'air

Assoupi de sommeils touffus.

Aimai-je un rêve?

delineia o poema que, portanto, consiste no ato mesmo de reconstituição do acontecimento, de modo que o fauno inevitavelmente se associa com a figura cabralina do "homem adormecido", em que se presentifica o sono e a nostalgia de mar alto. O motivo do sono aparece inclusive nos poemas de "Pedra do sono", seja no vulto de um poeta que se reconhece na figura de um "homem dormindo" (p. 46), seja na procura por perpetuar um acontecimento que se esvai (p. 84):

\footnotetext{
Os homens e as mulheres

adormecidos na praia

que nuvens procuram agarrar?
}

Nesse sentido, considerar o legado do fauno herdado pelo homem adormecido, permite conceber o fauno como uma matriz de um pensamento sobre a poesia e a filosofia desenvolvido sob o signo do sono e do sonho, em que a primeira poesia cabralina evidentemente se inscreve, de modo que, ao compartilhar um pensamento poeticamente similar ao mallarmeano, suscita questionamentos aos problemas fundados na dicotomia entre filosofia e poesia, da qual o homem adormecido se afasta iluminado 
pelas considerações sobre o fauno mallarmeano.

Ao constatar uma transformação crucial da relação entre a filosofia e a poesia na modernidade, Badiou afirma que o poema moderno, contrariando a dicotomia entre o poema e o matema em que se fundamenta a proscrição da poesia por Platão, consiste em um dever do pensamento ao mesmo tempo que se identifica a si mesmo como pensamento, constituindo o "conjunto das operações pelas quais esse pensamento se pensa" (Badiou, 1998, p. 36). Para tanto, Badiou evoca justamente "L'Aprés-midi d'un faune", por entender que evidencia o fato de que o poema moderno inverte o conceito de representação, de modo que exibe pela sua operação uma Ideia, cujo objeto e objetividade constituem imagens por meio das quais o poema potencialmente ultrapassa o objeto:

Em L'Aprés-midi d'un faune, de Mallarmé, o personagem que monologa, pergunta-se se existirá na natureza, na paisagem sensível, um traço possível do seu sonho sensual. Será que a água não apresenta a prova da frieza duma das mulheres desejadas? Será que o vento não recorda os suspiros voluptuosos da outra? Se é de afastar essa hipótese, é porque a água e o vento não são nada, face ao poder de suscitação por arte da ideia da água, da ideia do vento (Badiou, 1998, p. 37-38).

Antes de se ater propriamente ao significado do sono na obra mallarmeana, propondo uma filosofia do fauno, Badiou percorre, no horizonte dos limites entre a poesia e a filosofia, um caminho para compreender o poema mallarmeano. Badiou afirma que o poema moderno suspende a oposição entre imagem e Ideia, as quais, segundo Platão, seriam respectiva e exclusivamente apreendidas pela sensibilidade e pela inteligibilidade, uma vez que o poema moderno abandona o estatuto de imagem de um objeto que, por sua vez, consistiria na imagem da Ideia, a qual seria apreendida apenas dialeticamente, mediante a razão e em detrimento dos sentidos. Se, no extremo oposto da Ideia, concebida como verdade desprovida de realidade, Platão situa a poesia, a qual, na qualidade de representação, postula como sombra, a sombra dos objetos que, conforme a alegoria da caverna, os homens aprisionados, ao designar as sombras, "julgariam estar a nomear objetos reais" (Platão, 1996, p. 318), Badiou, por outro lado, entende que a poesia constitui um processo de verdade dos objetos apresentados pela linguagem, objetos retidos nos limites do seu desaparecimento ou presentificados no apagamento de sua objetividade, como se a imagem, por coextensividade, ascendesse ao estatuto de Ideia.

Nesse sentido, Badiou afirma que, com as palavras "Solitude, récif, étoile...", que justamente ilustram a folha de rosto de "Pedra do sono", de João Cabral, a poesia 
mallarmeana resume a transposição do objeto dos sentidos em Ideia, fundindo pela nomeação o referente relacionado com a palavra, para fazer existir intemporalmente o desaparecimento temporal do referido objeto. Aqui se inscreve o imperativo mallarmeano do enigma na poesia, fundado na impossibilidade de uma verdade presentificar ou nomear algo como verdade, o qual opera, conforme Badiou, segundo o poder do poema de "fixar eternamente o desaparecimento daquilo que se apresenta" ou presentificar a Ideia pela retenção do seu desaparecer, poder que, no entanto, o poema permanece "impotente para o nomear veridicamente" (Badiou, 1998, p. 43).

Segundo Badiou, o poeta reclama um "imperativo de desobjetivação" em nome de uma presentificação que denomina "noção pura", o que implica a "dissolução do objeto na sua pureza presente", processo imanente ao poema que o poeta denomina "transposição", a qual produz uma Ideia em detrimento de um objeto (Badiou, 1998, p. 48-49). Com efeito, o poeta concebe o verso como um "complemento superior" que "filosoficamente remunera" a linguagem (Mallarmé, 2010, p. 162). Para tanto, a poesia oferece, em detrimento da realidade das coisas, uma virtualidade manifesta na transposição de um fato de natureza em sua desaparição segundo o jogo da fala, emanando a "noção pura". Assim, "o dizer, antes de tudo, sonho e canto" encontra na poesia a "sua virtualidade", o que o autor profere com o consagrado enunciado: "Digo: uma flor!", concluindo que musicalmente se levanta como "ideia" a flor ausente (Mallarmé, 2010, p. 166-167). ${ }^{3}$

Sob o referido imperativo de desobjetivação, Badiou compreende que o crime do fauno consiste em fazer de um acontecimento um objeto, de modo que as ninfas se dissolvem nos braços do fauno que pretende fazer delas o objeto do seu desejo (Badiou, 1998, p. 188):

\footnotetext{
"Mon crime, c'est d'avoir, gai de vaincre ces peurs

Traitresses, divisé la touffe échevelée

De baisers que les dieux gardaient si bien mêlée:

Car, à peine j'allais cacher un rire ardent

Sous les replis heureux d'une seule (gardant

Par un doigt simple, afin que sa candeur de plume

Se teignît à l'émoi de sa soeur qui s'allume,

La petite, naïve et ne rougissant pas:)
}

\begin{abstract}
3 Ao observar o legado da teoria da imagem da poesia medieval para a poesia ocidental moderna, Giorgio Agamben constata que a poesia constitui o lugar da conciliação entre o desejo e o seu objeto, a imagem inscrita e conservada na fantasia. Agamben compreende que a poesia mallarmeana consiste em uma etapa fundamental em que o objeto de amor aparece como objeto perdido, e o poema, lugar do luto de um desejo encarcerado em seu desapossamento, representado justamente por "l'a absente de tout bouquet". Cf. Agamben, G. Estâncias: a palavra e o fantasma na cultura ocidental. Belo Horizonte: Editora UFMG, 2007, p. 213.
\end{abstract}


Que de mes bras, défaits par de vagues trépas,

Cette proie, à jamais ingrate se délivre

Sans pitié du sanglot dont j'étais encore ivre."

(Mallarmé, 1984, p. 52)

A objetificação na qual se perde o fauno convoca a perda, conclui Badiou, constatando que o acontecimento exige "um sujeito sem objeto" (Badiou, 1998, p. 189), assim como as ninfas exigiriam o desejo de um desejo em detrimento de um objeto.

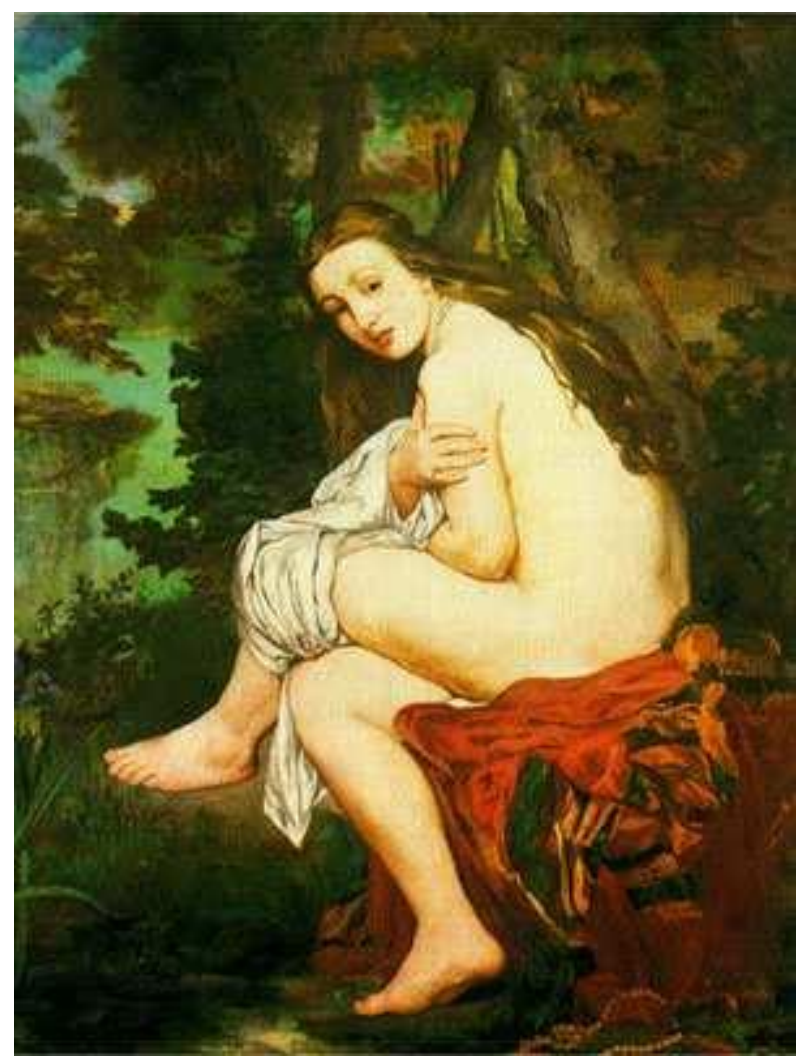

La ninfa sorprendida, pintada por Manet em 1861. Exposta no Museo Nacional de Bellas Artes de Buenos Aires, cujas paredes informam que aqui pela primeira vez o autor sugere alterações formais a um tema conhecido: a ninfa espreitada por faunos. ${ }^{4}$

Segundo Badiou, "L’Aprés-midi d'un faune" sugere um problema ao pensamento, a saber, a perpetuação de uma verdade por um sujeito apesar do desvanecimento do objeto, a partir da busca dos sinais de um acontecimento desvanecido, o qual se perpetua apenas por meio da nomeação pelo sujeito, que sustenta a confirmação do objeto. Badiou conclui que o programa geral do poema consiste em sustentar um sujeito pela fidelidade

4 As referidas alterações correspondem a uma representação carnal de uma ninfa reduzida a um nu feminino, mirando o espectador que assume o lugar do fauno. O que implica a relação entre sujeito e objeto, inclusive de desejo, e, ao manifestar criticamente em si instituições da pintura, ilustra a afirmação de Michel Foucault segundo a qual Manet evidencia, na pintura, os museus e as telas. 
ao nome de um acontecimento desaparecido, as ninfas que, sob o sono do fauno que ignora "se desperta ou se adormece", desaparecem (Badiou, 1998, p. 176-177).

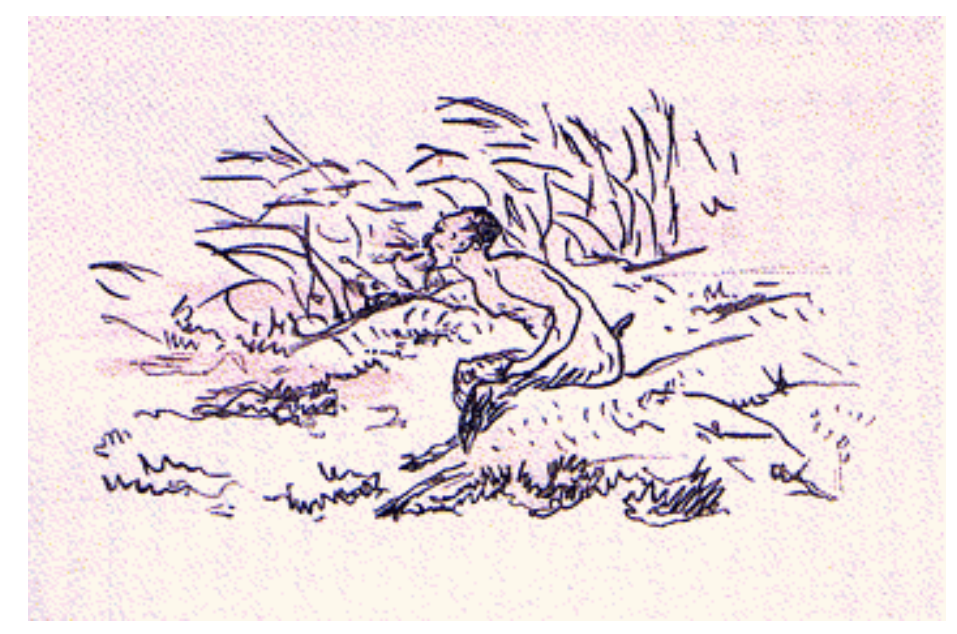

Desenho de Manet que ilustra a folha de rosto de "L'Après-midi d'un faune", publicado em 1876.

III.

O sono, finalmente, assume em “L'Aprés-midi d'un faune" um papel fundamental, constituindo a etapa final do processo de reconstituição do acontecimento pelo fauno. Afinal, o fauno, segundo Badiou, encontra por meio do sono a luz da sua verdade, ao questionar a Ideia representada no poema pela rainha:

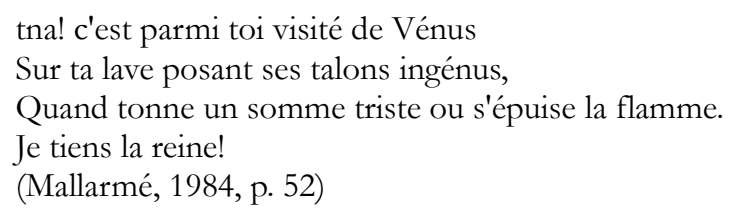

No poema, o sono se associa, portanto, a uma verdade, uma verdade suspensa, estando relacionado ao motivo terminal da sombra e de seu devir (Badiou, 1998, p. 192):

O sûr châtiment...

De paroles vacante et ce corps alourdi

Non, mais l'âme

Tard succombent au fier silence de midi:

Sans plus il faut dormir en l'oubli du blasphème,

Sur le sable altéré gisant et comme j'aime

Ouvrir ma bouche à l'astre efficace des vins!

Couple, adieu; je vais voir l'ombre que tu devins.

(Mallarmé, 1984, p. 52-53) 
A sombra do casal, evocada pelo poeta no verso final, constitui, segundo Badiou, o que o nome "Ces nymphes", caracterizado pela multiplicidade em detrimento da unidade de "la reine", induz no poema, de modo que a sombra constitui justamente a Ideia, a verdade do encontro das ninfas tal como o fauno se destina a perpetuar. Para tanto, o sono consiste na "imobilidade tenaz em que o fauno pode permanecer" (Badiou, 1998, p. 192), que, enfim, constitui o poema, ao final de um processo por meio do qual o fauno parece esgotar as operações da alma para reconstituir o acontecimento nomeado e, ao transcender dialeticamente a Ideia, inverter o procedimento para "ver o mundo superior" proposto por Platão: "Em primeiro lugar, olharia mais facilmente para as sombras, depois disso, para as imagens dos homens e dos outros objetos...", culminando com a contemplação da Ideia (Platão, 1996, p. 319). Afinal, o fauno, ao duvidar da rainha, a Ideia, anuncia que vai ver a sombra, o poema, cuja fidelidade reside entre o desaparecimento dos objetos nomeados e o anonimato do fauno entregue ao sono:

\footnotetext{
"Eu vou ver", muito simplesmente, o lugar donde o poema na sua globalidade foi possível. "Eu" vou escrever este poema. Esse ver do sono vai começar por: "Essas ninfas, eu quero perpetuá-las.” (Badiou, 1998, p. 193).
}

O sono, por fim, metaforiza, segundo Badiou, o sujeito mallarmeano da verdade da poesia, ao passo que a eternidade do nome, em torno da qual se cria uma verdade, pertence ao despertar do fauno determinado a perpetuar o acontecimento por meio do nome fixo: "Ces nymphes". "Do desejo que se liga o nome daquilo que desapareceu, depende que, revogado esse desejo, um sujeito seja urdido por essa verdade singular, que ele fez surgir sem o saber", conclui Badiou (1998, p. 195)..

Ora, o processo ao final do qual resulta o poema remete ao sono como predisposição para a poesia, segundo a tese cabralina, que o poeta surpreende inconscientemente sobre o papel na forma do poema, e que João Cabral concebe como vocação para o sobrenatural. Sobretudo se o sobrenatural evocado pela poesia se desdobrar etimologicamente revelando a relação, que persiste na filosofia e que se coloca em jogo na poesia, principalmente na figura do sonho, fundada em pares opostos que invariavelmente se fundamentam na noção de imagem, como a natureza e a liberdade, o sensível e o supra-sensível, o real e o ideal, o fenômeno e a coisa-em-si, etc.

A uma filosofia que compreende as imagens e, por conseguinte, a linguagem, pela incapacidade de apreender e compreender o mundo, a poesia mallarmeana oferece como contraproposta um "complemento superior" que "filosoficamente remunera" a linguagem (Mallarmé, 2010, p. 162), manifestando a capacidade da linguagem que Badiou 
concebe como "o poder de fixar eternamente o desaparecimento daquilo que se apresenta" (Badiou, 1998, p. 42). O que se coaduna com a poesia cabralina que completa e transcende "o livro e o jornal" cotidiano (p. 49), bem como com o sonho, a "linguagem natural" do sono, que o condiciona de modo que, pelo fato de estarmos adormecidos, presentifica objetivamente os acontecimentos "diante dos quais", ainda assim, "somos invariavelmente o preso, o condenado, o perseguido" (p. 686), segundo a tese cabralina. O sono, por outro lado, por escapar a uma percepção objetiva por parte do poeta, recusa assumir em sua obra o aspecto de "imagem", sem que "o poeta se sirva dele como uma linguagem" (p. 688), papel que cabe ao sonho.

A referida incapacidade de apreender e compreender o mundo por meio das imagens e, por conseguinte, da linguagem, encontra a sua representação por parte da filosofia em uma figura de aprisionamento, da qual a caverna de Platão constitui a mais famosa alegoria. Figura que os "Primeiros poemas" de João Cabral, que antecedem em poucos anos "Pedra do sono", anunciam sob o signo de "cordas" e "amarras" (p. 805):

Deixa que os não-poetas falem de tua beleza, esses nunca compreenderão o que há em ti de sombra de sementes germinando, de vozes de cavernas.

e, sob a sombra, que se relaciona, no poema mallarmeano, ao sono, conforme Badiou, reconhecem na poesia "a voz imensa que dorme no mistério" (p. 807):

Deixa, que tudo só frutificará

na atmosfera sobrenatural da poesia.

A figura de aprisionamento, que ilustra a incapacidade de apreender e compreender o mundo por meio das imagens e, por conseguinte, da linguagem, se associa com uma concepção de percepção segundo a qual o objeto desaparece sem o sujeito, concepção cartesiana que se traduz na seguinte formulação kantiana: "nenhum objeto sem sujeito" (Schopenhauer, 2005, p. 546), o qual encontra um correlato na formulação schopenhaueriana: "O mundo é minha representação" (Schopenhauer, 2005, p. 43). Seja como um problema da razão, seja como um problema da representação, ambas postulam que o mundo existe apenas como objeto do sujeito, ou seja, que "o que existe para o conhecimento, portanto o mundo inteiro" se reduz a "objeto em relação ao sujeito", o que requer a "divisão em sujeito e objeto", que constitui a "forma comum de todas as classes" de representações, segundo Schopenhauer (2005, p. 43).

A despeito, portanto, de uma filosofia que desconfia das imagens e, no limite, da 
realidade, e para a qual o sonho representa tanto um problema quanto o oposto da realidade, a poesia oferece a possibilidade de se conceber uma linguagem capaz de apreender e compreender o mundo imediatamente por meio das imagens, o que o sonho representa na poesia. Tanto que a "questão acerca da realidade do mundo exterior", que ocupa a filosofia, encontra a sua origem justamente no sonho: "Temos sonhos. Não seria toda a vida um sonho?", questiona Schopenhauer (2005, p. 58), preocupado em distinguir o sonho da realidade, concluindo que o despertar, com o consequente rompimento do encadeamento causal entre os acontecimentos sonhados e os da vida desperta, representa o meio para diferenciar a ambos.

Nesse sentido, a operação badiouana consiste essencialmente em reler a tradição de uma filosofia que relega a arte a uma degradação da Ideia em imagem, postulando, em contraposição, o objeto dos sentidos, o ser da imagem, como a criação natural da Ideia. ${ }^{5}$ E a referida operação implica a superação da oposição entre sujeito e objeto, na medida em que o acontecimento, conforme a filosofia do fauno proposta por Badiou, exige "um sujeito sem objeto" (Badiou, 1998, p. 189). E, invertendo a proposição badiouana, que afinal postula um sujeito impessoal a despeito do objeto, a concepção de um objeto sem sujeito permitiria, por outro lado, pensar o objeto de modo imediato e independente do sujeito. Para tanto, o sonho, "linguagem natural" do sono conforme a tese cabralina - e "natural" condiz com o ser da imagem ou da sombra - oferece, segundo Emanuele Coccia, um pensamento em que a natureza deixa de ser definida pelo sujeito, de modo que a oposição entre o eu e o mundo desaparece. Nesse entrecruzamento, permitido apenas pelas imagens, o sonho constitui a forma suprema da intimidade de todo vivente, a qual transfunde, no entanto, o sujeito nas coisas:

5 Cfr. Ludueña, F. J. "Eternidad, espectralidad, ontologia: hacia uma estética trans-objetual”, In: BADIOU, A. Pequeño manual de inestética. Buenos Aires: Prometeo Libros, 2009, p. 16. Ao constatar que perdura em Badiou uma concepção inferiorizante de estética enquanto ciência da sensação e do sensível, Fabián Ludueña atribui a Badiou um "realismo de la Idea", inscrevendo-o em uma vertente estritamente realista e platonizante, bem como hegeliana, na medida em que "la Idea es, primariamente para Badiou, el objeto de toda estética y, en consonancia con ello, también la multiplicidad de verdades eternas que advienen con ella." Assim, Badiou privilegia a "esfera inteligible de lo bello estético en detrimento de la existencia primaria sensible de todo objeto estético." Ludueña compreende que Hegel, mais que Kant, provoca definitivamente o divórcio entre a estética, para a qual a arte seria a representação do Ideal, de modo que a imediação natural seria somente signo da ideia, e a ciência do sensível, o que deriva na autonomização da ciência do belo: "El radical gesto hegeliano de separar a la ciencia de lo bello de la ciencia de lo estrictamente sensible ha perdurado hasta hoy como acto inaugural y decisivo del cual ninguna estética antihegeliana ha podido desembarazarse del todo". Nesse sentido, o legado badiouano para a reflexão estética, segundo Ludueña, consiste no postulado de que não existe um território autônomo da ciência do belo, de modo que a filosofia badiouana articula as noções de sensível e de Ideia. A estética deve, assim, ser reconduzida a seu âmbito ontológico mais próprio, ou seja, das imagens sensíveis, se se pretende verdadeiramente refletir sobre o que pode ser a arte. 
No sonho, a vida sensível se torna tão intensa que "parece um tipo de vida, mesmo que menor e existente em uma natureza própria”, escreveu Sinésio de Cirene no mais belo tratado sobre os sonhos já escrito no Ocidente. Cada vez que sonhamos, explica Sinésio, "vemos cores, ouvimos sons, percebemos sensações táteis nítidas mesmo que os órgãos de nosso corpo não estejam ativos” (Coccia, 2010, p.62).

Coccia conclui que no sonho coincidimos materialmente com o meio de conhecimento, as imagens (Coccia, 2010, p.63), por meio das quais a vida pode ser transmitida, sendo o sonho o que permite ao vivente transmitir a si mesmo as verdades mais secretas. O sonho, assim, constitui o lugar privilegiado "da transmissão de todas as verdades", bem como de "comunicação", tanto "dos vivos com os mortos", quanto "do sujeito consigo mesmo": "Então, se a imagem é o lugar em que o humano se torna transmissível, toda imagem é como um fragmento de sonho" (Coccia, 2010, p.71).

Ao espreitar a sombra que conforma o sonho, João Cabral o concebe como uma obra, um poema produzido por meio da reconstituição do sonho, o qual, como a poesia, pode ser transmitido, assim como a imagem constitui um meio de transmissão da vida e da verdade, segundo Coccia. Resta indagar se a sombra do sonho reivindicada por João Cabral seria, enfim, a mesma sombra do fauno, a qual representa o motivo terminal do poema e o poema mesmo. Se o fauno compartilha a mesma sombra com o homem dormindo. Se o sopro noturno do sono, que fecunda a poesia, assopra a flauta do fauno que, afinal, induz ao sono.

\section{IV.}

Perscrutar a sombra do sonho reivindicada por João Cabral significa contrariar as leituras tradicionais que, em detrimento da obscuridade da primeira poesia cabralina influenciada pelo sono que despersonaliza o poeta, demandam invariavelmente a claridade da razão, iluminadas pela leitura inaugural de Antonio Candido. ${ }^{6}$ Leituras que se sustentam no mito fundador da modernidade que confina o mundo e a vida no sujeito cognoscente, supostamente dotado de autonomia, e cuja demanda da luz do Sol constitui um "meio de encaminhar o legado mallarmeano para uma cena de luz diurna" (Costa Lima, 2000, p.56), ${ }^{7}$ conforme uma gradativa comunicabilidade que se consolidaria com o

6 Cf. Candido, A. (1943). "Poesia ao norte”. In: Colóquio Letras. Paisagem tipográfica: homenagem a João Cabral de Melo Neto (1920-1999), Lisboa, n. 157/158, p. 15-19, jun./dez. 2000.

7 Costa Lima, L. “João Cabral: poeta crítico". In: Colóquio Letras. Paisagem tipográfica: homenagem a João Cabral de Melo Neto (1920-1999), Lisboa, n. 157/158, jun./dez. 2000, p. 56. Outro artigo exemplar da mesma perspectiva apresentada por Luiz Costa Lima se encontra em ALMINO, João. 'O domador de sonhos' e outras imagens da pedra: a construção da poética de João Cabral de Melo Neto de "Pedra do sono" a "A educação pela pedra". In: Colóquio Letras. Paisagem tipográfica: homenagem a João Cabral de 
rigor formal de sua engenharia na mesma medida em que se afastaria do sono e do sonho.

Significa ainda identificar na primeira poesia cabralina um reflexo da teoria da imagem, situada, segundo Giorgio Agamben, sob o signo do desejo, cumprindo, inclusive, um papel essencial no sonho (Agamben, 2007, 133-136). Abandonada pela filosofia, a teoria da imagem encontra asilo justamente na poesia, que se torna o lugar da conciliação entre o desejo, fundamento e sentido de uma poesia associada com a imagem, e o seu objeto, ecoando ainda na poesia mallarmeana (Agamben, 2007, 213). Nesse sentido, a poesia cabralina parece se fundamentar na sensibilidade, a qual define, por meio das imagens, a nossa forma de vida, conforme Coccia (2010, p.60), sendo o sonho o lugar em que as imagens exercem sua autonomia, e o sono, a despersonalização do sujeito cognoscente. E a via para tanto se encontra, a despeito da psicologia, na poesia. Afinal, o poeta busca a sombra ignorada pela psicologia, a qual, ao compreender o sonho como a realização dos desejos e, por conseguinte, como objeto de interpretação, procura, ainda, racionalizar os sonhos.

Justamente ao constatar o aspecto irracional de uma poesia elaborada sobre os dados da sensibilidade, Candido intui tanto o papel fundamental da imagem na poesia cabralina, quanto o legado da poesia mallarmeana, embora o considere, ansioso por uma comunicabilidade que justificaria a obra de arte, o erro de sua poesia. O poeta mesmo parece recusar, anos depois, o sonho, concebido agora como signo de obscuridade, oposto ao verso preciso e claro, ao escrever que a "folha branca" em que imprime seus versos "proscreve o sonho" (p.93). Assim como parece recusar o legado mallarmeano, ao questionar o sentido em que ainda escreve a poesia (p.101):

\section{flor! Não uma}

flor...

reitera o poeta se referindo aparentemente ao consagrado enunciado mallarmeano: "Digo: uma flor!". O que parece indicar a janela aberta pelo poeta ao permitir incidir sobre sua poesia a claridade emanada da demandada luz do Sol.

O melhor, porém, meu caro melancólico, é dormir muito, em sentido próprio e impróprio! Assim teremos novamente a nossa manhã! A peça de arte, na sabedoria de viver, é saber intercalar o sono de toda espécie no momento certo (Niestzche, 2004, p. 208). ${ }^{8}$

Melo Neto (1920-1999), Lisboa, n. 157/158, p. 127-158, jun./dez. 2000.

8 Nietzsche emprega aqui as figuras da melancolia, que, segundo Agamben, corresponde ao poder de fazer aparecer como perdido um objeto de desejo inscrito na fantasia, bem como a duplicidade do significar 


\section{Referências bibliográficas}

AGAMBEN, Giorgio. Estâncias: a palavra e o fantasma na cultura ocidental. Belo Horizonte: Editora UFMG, 2007.

BADIOU, Alain. Pequeno manual de inestética. Lisboa: Instituto Piaget, 1998.

CANDIDO, A. (1943). Poesia ao norte. In: Colóquio Letras. Paisagem tipográfica: homenagem a João Cabral de Melo Neto (1920-1999), Lisboa, n. 157/158, p. 15-19, jun./dez. 2000.

COCCIA, Emanuele. A vida sensivel. Florianópolis: Cultura e Barbárie, 2010.

COSTA LIMA, L. João Cabral: poeta crítico. In: Colóquio Letras. Paisagem tipográfica: homenagem a João Cabral de Melo Neto (1920-1999), Lisboa, n. 157/158, jun./dez. 2000.

LUDUEÑA, Fabián J. Eternidad, espectralidad, ontologia: hacia uma estética trans-objetual. In: BADIOU, Alain. Pequeño manual de inestética. Buenos Aires: Prometeo Libros, 2009.

MALLARMÉ, Stéphane. Divagações. Florianópolis: Ed. da UFSC, 2010.

MALLARMÉ, Stéphane. Oeuvres completes. Paris: Gallimard, 1984.

MELO NETO, João Cabral. Obra completa. Rio de Janeiro: Nova Aguilar, 1994.

NIETZSCHE, Friedrich Wilhelm. Aurora: reflexões sobre os preconceitos morais. São Paulo: Companhia das Letras, 2004.

PLATÃO. A república. 8. ed. Lisboa: Fundação Calouste Gulbenkian, 1996.

SCHOPENHAUER, Arthur. O mundo como vontade e como representação. São Paulo: Ed. UNESP, 2005.

manifesta na oposição entre o próprio e o impróprio, a qual, ainda segundo Agamben, seria recuperada por Freud para designar a oposição entre um discurso consciente e um inconsciente, respectivamente. Cf. Agamben, 2007, p. 225 et seq. 